BACKGROUND: Low-dose and long-term administration of macrolide antibiotics into patients with chronic airway inflammatory diseases could favorably modify their clinical conditions. However, the therapeutic mode of action of macrolides is not well understood. Free oxygen radicals, including nitric oxide (NO), are well recognized as the important final effector molecules in the development and the maintenance of inflammatory diseases.

Purpose: The influence of macrolide antibiotics on NO generation was examined in vivo.

Methods: Male ICR mice, 5 weeks of age, were orally administered with either roxithromycin, clarithromycin, azithromycin or josamycin once a day for 2-4 weeks. The mice were then injected intraperitoneally with $5.0 \mathrm{mg} / \mathrm{kg}$ lipopolysaccharide (LPS) and the plasma NO level was examined $6 \mathrm{~h}$ later.

Results: Although pre-treatment of mice with macrolide antibiotics for 2 weeks scarcely affected NO generation by LPS injection, the administration of macrolide antibiotics, except for josamycin, for 4 weeks significantly inhibited LPS-induced NO generation. The data in the present study also showed that pre-treatment of mice with macrolide antibiotics for 4 weeks significantly suppresses not only production of pro-inflammatory cytokines interleukin-1 $\beta$, interleukin-6, and tumor necrosis factor- $\alpha$, but also inducible nitric oxide synthase mRNA expressions, which are enhanced by LPS injection.

Conclusion: These results strongly suggest that suppressive activity of macrolide antibiotics on NO generation in response to LPS stimulation in vivo may, in part, account for the clinical efficacy of macrolides on chronic inflammatory diseases.

Key words: Macrolide antibiotics, Nitric oxide, Mouse, Inducible nitric oxide synthase mRNA, Pro-inflammatory cytokine, Suppression, In vivo

\section{Suppressive activity of macrolide antibiotics on nitric oxide production by lipopolysaccharide stimulation in mice}

Hajime Terao ${ }^{1}$, Kazuhito Asano ${ }^{2}$, Ken-ichi Kanai ${ }^{1}$, Yoshiyuki Kyo ${ }^{1}$, So Watanabe ${ }^{1}$, Tadashi Hisamitsu ${ }^{2}$ and Harumi Suzaki ${ }^{1, C A}$

${ }^{1}$ Department of Otolaryngology and ${ }^{2}$ Department of Physiology, School of Medicine, Showa University, 15-8 Hatanodai, Shinagawa-Ku, Tokyo 142-8666, Japan

\author{
${ }^{\mathrm{CA}}$ Corresponding Author \\ Tel: +81337848676 \\ Fax: +8133784 3757 \\ E-mail: h-suzaki@mve.biglobe.ne.jp
}

\section{Introduction}

Low-dose and long-term administration of macrolide antibiotics, so-called macrolide therapy, is reported to be effective in the treatment and the management of chronic inflammatory diseases, such as diffuse panbronchiolitis and chronic sinusitis. ${ }^{1,2}$ It is also observed that administration of azithromycin (AZM), a newly developed 15-membered macrolide antibiotic, could modify the clinical condition of cystic fibrosis. ${ }^{3,4}$ Although the precise mechanisms of the macrolide therapy are not well understood, there is circumstantial evidence that the therapeutic mode of macrolides is due in part to their anti-inflammatory, rather than antibacterial, effects. ${ }^{2,5,6}$

It is reported that an accumulation of both neutrophils and macrophages in the airway is an important feature of the diseases, which is normalized after appropriate macrolide therapies. ${ }^{7}$ It is also recognized that, in response to antigenic stimulation, these inflammatory cells can secret not only inflammatory cytokines, but also free oxygen radicals such as $\mathrm{O}_{2}^{-}$and $\mathrm{H}_{2} \mathrm{O}_{2}{ }^{8,9}$ Our previous work clearly shows the suppressive activity of macrolide antibiotics on inflammatory cytokine production from inflammatory cells, including $\mathrm{T}$ cells, mast cells and macrophages in vitro and in vivo. ${ }^{5,8,10}$ However, there is little information about the influence of macrolide antibiotics on free oxygen radical generation from inflammatory cells. ${ }^{9}$

Nitric oxide (NO) is recognized as one of the important regulators of many cell and tissue functions. It is also accepted NO is produced from various types of cells and tissues (e.g. skeletal muscle, epithelium and fibroblasts) in response to inflammatory stimuli. ${ }^{11}$ Although $\mathrm{NO}$ is generally believed to be a short-lived gaseous free radical, it reacts extremely rapidly with superoxide and produces the very reactive and toxic peroxinitrite, which 
subsequently decomposes into additional highly reactive intermediates. ${ }^{11,12}$ Clinical evidence has clearly shown that NO concentration in exhaled air is increased in patients with airway inflammations, including rhinitis, as compared with normal subjects. ${ }^{13,14}$ Recently, nitrogen derived from oxidants was found to play a role in airway diseases as one of the final effector molecules, ${ }^{15}$ suggesting the possibility of an important role for peroxynitrite in inflammatory airway diseases. Recent in vitro studies clearly showed that macrolide antibiotics, such as erythromycin and roxithromycin (RXM), significantly suppress NO generation from both macrophages and nasal fibroblasts in response to inflammatory stimuli. ${ }^{16,17}$ These reports may suggest that macrolide antibiotics exert an attenuating effect on chronic inflammatory diseases through suppression of $\mathrm{NO}$ generation. However, before drawing the conclusion that this suppressive activity of macrolide antibiotics underlies one of the therapeutic modes of action of agents on the diseases, it is necessary to examine whether macrolide antibiotics could also suppress NO generation in vivo. In the present study, therefore, we examined the influence of macrolide antibiotics on NO generation in vivo using an experimental mouse model.

\section{Materials and methods}

\section{Mouse}

Specific pathogen free ICR mice were purchased from Charles River Japan Inc. (Atsugi, Japan). After arrival at our university, they were kept in filter $(0.2$ $\mu \mathrm{m}$ )-barriered cages, and provided with autoclaved food and tap water ad libitum throughout the experiments to prevent un-wanted microbiological infection. The rats were all male and 5 weeks of age at the start of experiments. All animal experimental procedures were approved by the Animal Care and Use Committee of Showa University and were carried out in accordance with the guidelines of the Physiological Society of Japan.

\section{Antibiotics}

RXM was kindly donated by Aventis Pharmaceutical Co. Ltd (Tokyo, Japan) as a water-insoluble, preservative-free pure powder. This agent was well mixed with 5\% tragacanthogum solution at 20.0 $\mathrm{mg} / \mathrm{ml}$ and diluted with normal saline to give a concentration of $2.0 \mathrm{mg} / \mathrm{ml}$. The mice were given 2.5 $\mathrm{mg} / \mathrm{kg}$ of RXM, one-half of the recommended human therapeutic dose, once a day for 2-4 weeks via a stomach tube. Clarithromycin (CAM) was also a gift from Abott Japan Co. Ltd. (Tokyo, Japan) as a preservative-free pure powder. CAM, dissolved in normal saline as in the case of RXM, was orally administered into mice at a dose of $7.0 \mathrm{mg} / \mathrm{kg}$, onehalf of the recommended human therapeutic dose, once a day for 4 weeks. Josamycin (JM) was purchased from SIGMA Chemicals (St Louis, MO, USA) and dissolved in normal saline as was RXM. JM was also administered orally into mice at a dose of $20.0 \mathrm{mg} / \mathrm{kg}$, the recommended human therapeutic dose, once a day for 4 weeks. AZM was extracted from ZITHROMAC dry syrup (Pfizer Co. Ltd., Tokyo, Japan) for pediatoric use, which contains $100.0 \mathrm{mg}$ of AZM, Yellow 5 and sodium lauryl sulfate. AZM was dissolved by suspending dry syrup in $5.0 \mathrm{ml}$ of ethanol, and then homogenized with a sonic dismembrator for $5 \mathrm{~min}$ at $4^{\circ} \mathrm{C}$, and centrifuged at 5000 $\mathrm{rpm}$ for $15 \mathrm{~min}$ at $4^{\circ} \mathrm{C}$. The supernatants were collected and the ethanol was evaporated. The resultant powder was dissolved in saline as RXM administered orally into mice at a dose of $8 \mathrm{mg} / \mathrm{kg}$ once a day for 4 weeks. In all cases, the volume administered did not exceed $0.2 \mathrm{ml}$, and control mice received 5\% tragacanthogum solution alone.

\section{Lipopolysaccharide treatment}

Mice were injected intraperitoneally with lipopolysaccharide (LPS) derived from Escherichia coli (SIGMA Chemicals) in a volume of $0.5 \mathrm{ml}$.

\section{Preparation of plasma}

Blood $(1.0 \mathrm{ml})$ was obtained from cardiac puncture in the presence of $0.1 \mathrm{ml}$ of heparin, and then centrifuged at $3000 \mathrm{rpm}$ for $10 \mathrm{~min}$ at $4^{\circ} \mathrm{C}$. Plasma was obtained and stored at $-40^{\circ} \mathrm{C}$ until used.

\section{Assay for $\mathrm{NO}\left(\mathrm{NO}_{2}^{-} / \mathrm{NO}_{3}^{-}\right)$}

To remove proteins from plasma, samples were filtered through centrifugal ultrafiltration devices at $5000 \times \mathrm{g}$ for $30 \mathrm{~min}$ at $4^{\circ} \mathrm{C}$ (Centricon YM-10; cut-off molecular weight, 10,000; Millipore Corp., Bedford, MA, USA). The NO levels in samples were examined by a NO assay kit that contained sufficient reagents (DojinDo, Co., Ltd, Kumamoto, Japan).

\section{Assay for cytokines}

Interleukin (IL)-1 $1 \beta$, IL- 6 and tumor necrosis factor- $\alpha$ (TNF- $\alpha$ ) levels in plasma were examined using commercially available mouse cytokine enzymelinked immunosorbent assay kits (R \& D Corp., Minneapolis, MN, USA). The sensitivity of these kits for IL- $1 \beta$, IL- 6 , and TNF- $\alpha$ was $3.0 \mathrm{pg} / \mathrm{ml}, 7.0 \mathrm{pg} / \mathrm{ml}$, and $2.0 \mathrm{pg} / \mathrm{ml}$, respectively. 


\section{Assay for inducible nitric oxide synthase mRNA} expression

The lungs were obtained from mice after decapitation, and homogenized with a glass homogenizer at $4^{\circ} \mathrm{C}$ for $60 \mathrm{sec}$. Poly $\mathrm{A}^{+}$mRNA was separated from homogenates with oligo(dT)-coated magnetic microbeads (Milteny Biotec, Bergische Gladbach, Germany). Inducible nitric oxide synthase (iNOS) mRNA was examined with mouse iNOS mRNA enzymelinked immunosorbent assay test kits (R \& D Corp.) according to the recommended manufacturer's protocol.

\section{Statistical analysis}

Data were analyzed with analysis of variance followed by Fisher's PLSD test. $p<0.05$ was considered significant.

\section{Results}

\section{Influence of macrolide antibiotics on NO production by LPS stimulation in vivo}

The first experiments were undertaken to examine the time course of NO production after LPS injection.
Plasma was obtained from mice 3, 5, 6, 7, and $8 \mathrm{~h}$ after injection of $5.0 \mathrm{mg} / \mathrm{kg}$ of LPS, and NO levels were examined. As shown in Fig. 1, intraperitoneal injection of LPS caused a transient increase in NO levels in plasma. NO levels in plasma gradually increased, peaked at 6-7 h, and decreased to control levels by $8 \mathrm{~h}$ after LPS injection.

The next experiments were carried out to examine the optimum concentration of LPS to induce NO production in mice. Donor mice were given intraperitoneal injections of $1.0,2.5,5.0$, and $6.0 \mathrm{mg} / \mathrm{kg}$ of LPS, and plasma NO levels were examined $5 \mathrm{~h}$ later. The data in Fig. 2 shows that LPS injection of $1.0 \mathrm{mg} /$ $\mathrm{kg}$ caused a significant increase in NO levels in plasma. NO levels in plasma were further increased when more than $5.0 \mathrm{mg} / \mathrm{kg}$ of LPS was used for stimulation of $\mathrm{NO}$ production.

We then examined the influence of macrolide antibiotics on NO production in response to LPS stimulation in vivo. To do this, mice were pre-treated with $2.5 \mathrm{mg} / \mathrm{kg} /$ day of RXM for $2-4$ weeks. These mice received intraperitoneal injections of $5.0 \mathrm{mg} / \mathrm{kg}$ of LPS, and plasma NO levels were examined $5 \mathrm{~h}$ later. Although pre-treatment of mice with RXM for 2 weeks did not affect NO production in response to LPS stimulation in vivo, pre-treatment for longer periods ( 4 weeks) could suppress the ability of

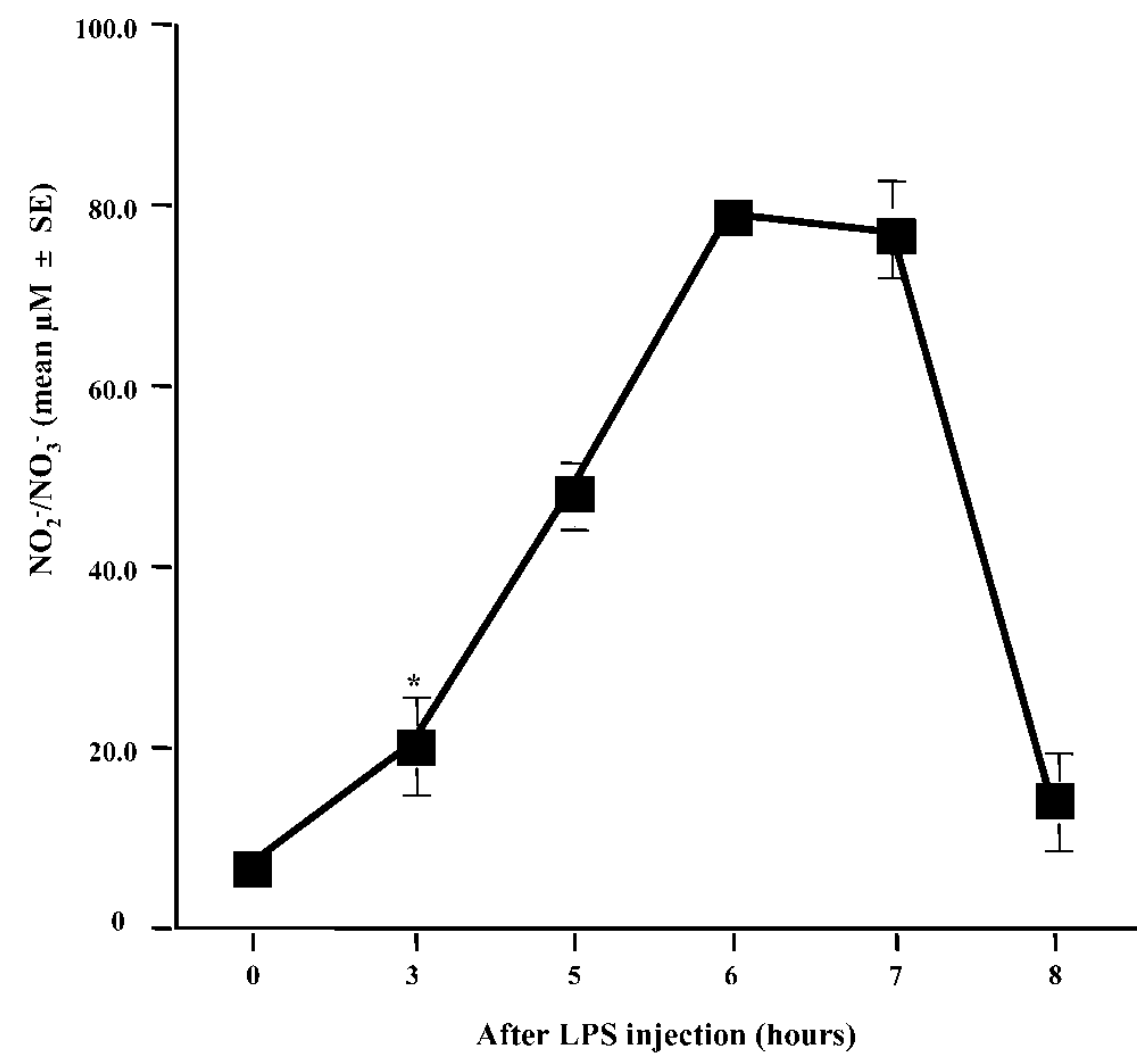

FIG. 1. Time course of $\mathrm{NO}\left(\mathrm{NO}_{2}^{-} / \mathrm{NO}_{3}^{-}\right)$generation after LPS injection in mice. ICR mice were injected intraperitoneally with 5.0 $\mathrm{mg} / \mathrm{kg}$ of LPS, and plasma $\mathrm{NO}_{2}^{-} / \mathrm{NO}_{3}^{-}$levels were examined at 3,5, 6, 7, and $8 \mathrm{~h}$ after injection. The data are expressed as the mean $(\mu \mathrm{M}) \pm$ standard error of five mice. * Significant compared with normal control $(0 \mathrm{~h})$. 


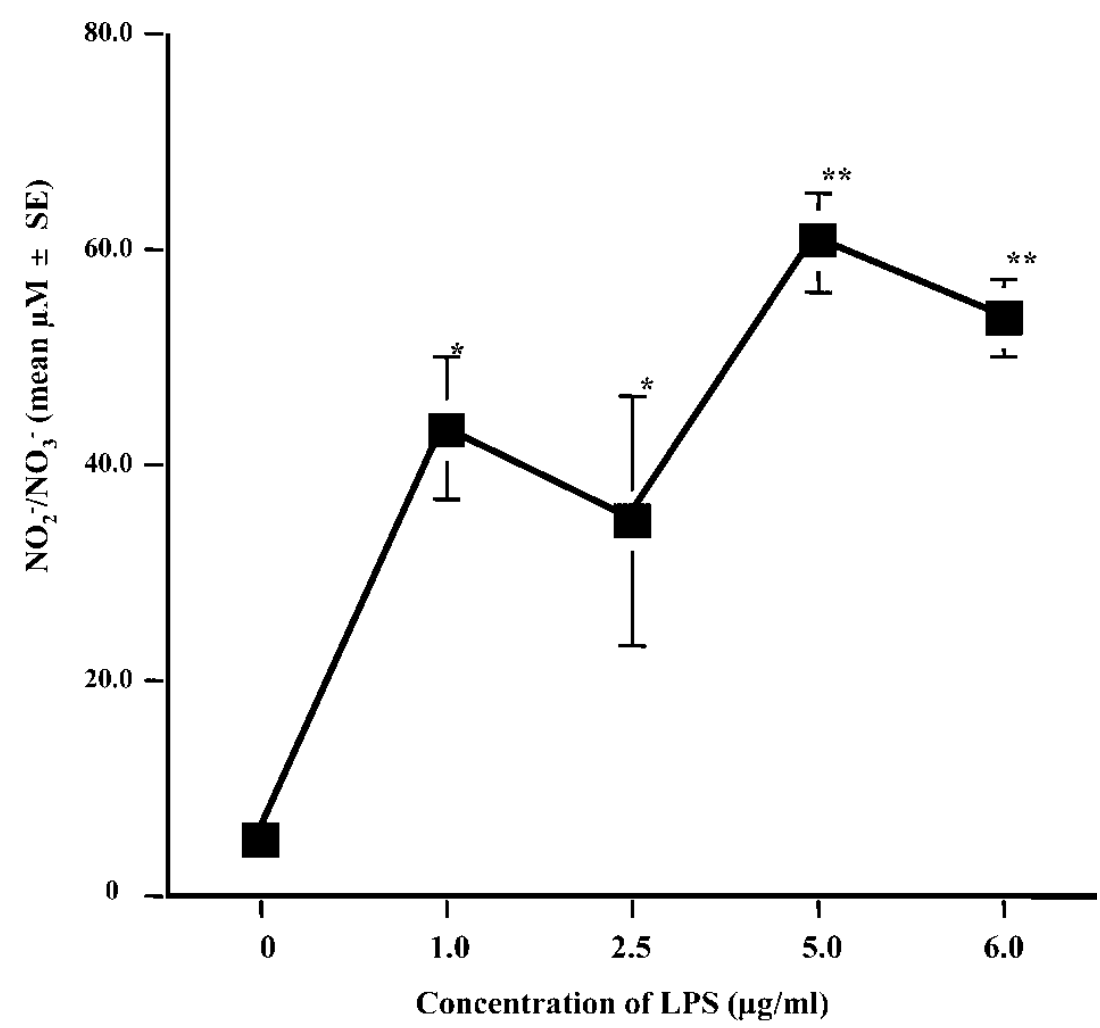

FIG. 2. Dose-response profile of $\mathrm{NO}\left(\mathrm{NO}_{2}^{-} / \mathrm{NO}_{3}^{-}\right)$generation by LPS injection in mice. ICR mice were injected intraperitoneally with various concentrations of LPS, and plasma was obtained $6 \mathrm{~h}$ later to assay $\mathrm{NO}_{2}^{-} / \mathrm{NO}_{3}^{-}$levels. The data are expressed as the mean $(\mu \mathrm{M}) \pm$ standard error of five mice. * Significant compared with normal control $(0 \mu \mathrm{g} / \mathrm{kg}) ; *$ * significant compared with $2.5 \mathrm{mg} / \mathrm{kg}$ of LPS.

mice to produce NO after LPS stimulation (Fig. 3). We further examined whether macrolide antibiotics except for RXM could also exert a suppressive effect on
NO production induced by LPS stimulation. As shown in Fig. 4, AZM and CAM, but not JM, completely suppressed NO production induced by

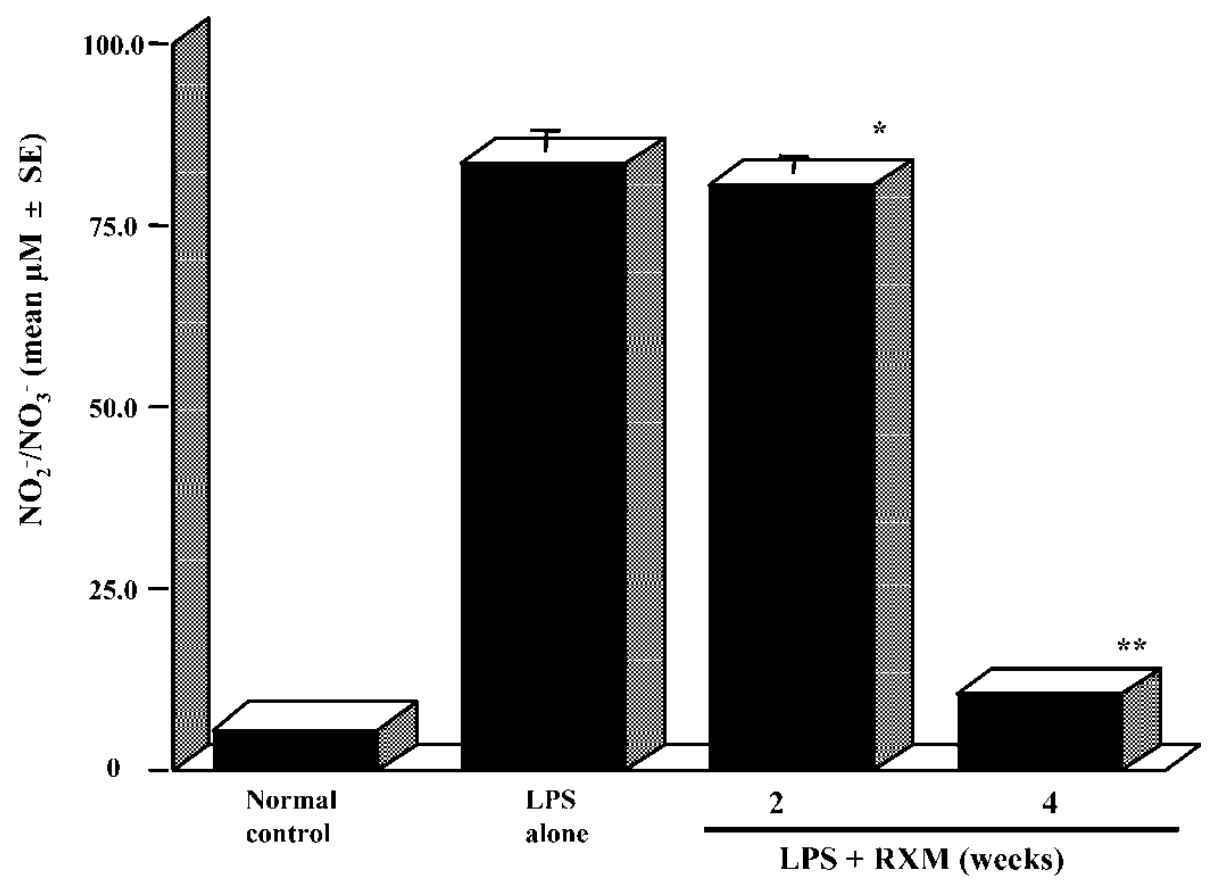

FIG. 3. Influence of RXM on NO $\left(\mathrm{NO}_{2}^{-} / \mathrm{NO}_{3}^{-}\right)$generation in response to LPS injection. ICR mice were administered orally with RXM once a day for 2 and 4 weeks at a dose of $2.5 \mathrm{mg} / \mathrm{kg}$ of RXM. The mice were then injected intraperitoneally with $5.0 \mathrm{mg} / \mathrm{kg}$ of LPS, and plasma $\mathrm{NO}_{2}^{-} / \mathrm{NO}_{3}^{-}$levels were examined $6 \mathrm{~h}$ later. The data are expressed as the mean $(\mu \mathrm{M}) \pm$ standard error of five mice. * Not significant compared with LPS alone; ** significant compared with LPS alone. 


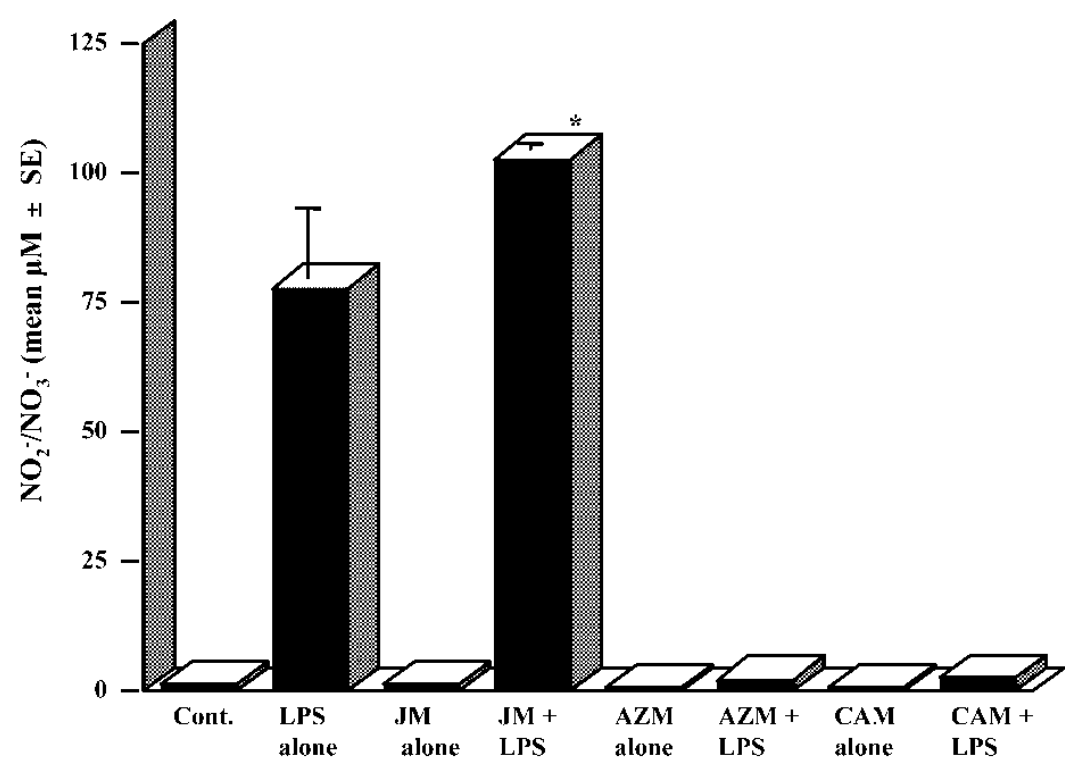

FIG. 4. Influence of several types of macrolide antibiotics on $\mathrm{NO}\left(\mathrm{NO}_{2}^{-} / \mathrm{NO}_{3}^{-}\right)$generation in response to LPS injection.ICR mice were administered orally with either JM, AZM, or CAM once a day for 4 weeks. The mice were then injected intraperitoneally with $5.0 \mathrm{mg} / \mathrm{kg}$ of LPS, and plasma $\mathrm{NO}_{2}^{-} / \mathrm{NO}_{3}^{-}$levels were examined $6 \mathrm{~h}$ later. The data are expressed as the mean $(\mu \mathrm{M}) \pm$ standard error of five mice. * Not significant compared with LPS alone.

LPS stimulation. The data in Fig. 4 also show that the suppressive activity of AZM and CAM on NO production was much stronger than that of RXM.

\section{Influence of macrolide antibiotics on pro- inflammatory cytokine appearance in plasma after LPS injection}

The present experiments were performed to examine the influence of macrolide antibiotics on pro-inflammatory cytokine production by LPS injection. We first examined the time course of pro-inflammatory cytokine, IL-1 $\beta$, IL- 6 and TNF- $\alpha$ production after LPS injection. Normal mice were injected intraperitoneally with $5.0 \mathrm{mg} / \mathrm{kg}$ of LPS, and plasma samples were obtained 0 (before LPS injection), 1, 2, 3, and $4 \mathrm{~h}$ after LPS injection. As shown in Fig. 5 (upper panels), LPS injection caused a transient increase in pro-inflammatory cytokine levels in plasma; IL-1 $\beta$ and IL-6 levels in plasma peaked at $2 \mathrm{~h}$, and then decreased to normal levels (before LPS injection) by $4 \mathrm{~h}$. TNF- $\alpha$ levels in plasma also showed a similar pattern to those observed in IL-1 $\beta$ and IL-6, peaking $1 \mathrm{~h}$ after LPS injection and then decreasing to normal levels by $3 \mathrm{~h}$. We next examined whether pre-treatment of mice with macrolide antibiotics could suppress proinflammatory cytokine production induced by LPS injection. Mice were pre-treated orally either with RXM, AZM, CAM or with JM once a day for 4 weeks. They were then injected intraperitoneally with 5.0 $\mathrm{mg} / \mathrm{kg}$ of LPS, and plasma was obtained $1 \mathrm{~h}$ later for TNF- $\alpha$ assay, and 2 h later for IL-1 $\beta$ and IL- 6 assays. As shown in Fig. 5 (lower panels), macrolide antibiotics without JM significantly suppress cytokine levels in plasma.

\section{Influence of macrolide antibiotics on iNOS mRNA expression in lung after LPS injection}

The final experiments were designed to examine the influence of macrolide antibiotics on iNOS mRNA expression induced by LPS injection. The data in Fig. 6 clearly show that macrolide antibiotics without JM significantly suppress iNOS mRNA expression in the lung, which was increased by LPS injection.

\section{Discussion}

Macrolide antibiotics are well known to be effective against Gram-positive bacteria and are frequently used in the treatment of upper and lower respiratory tract infections. Since the initial success of treatment of diffuse panbronchiolitis with erythromycin, the most famous 14-membered macrolide antibiotic, for longer than 3 months was reported by Kudoh et al., ${ }^{18}$ this therapy was used for the treatment and the management of airway inflammatory diseases, including chronic sinusitis with remarkable success., ${ }^{1,2}$ Much effort has been made to understand the mechanisms underlying the clinical efficacy of macrolides, and has revealed that the anti-inflammatory action of macrolides, but not bactericidal activity, is responsible for the effectiveness of macrolide therapy. ${ }^{5,6,8-10}$ However, the precise mechanisms are not well understood. The present results strongly suggest that the suppressive activity of macrolide antibiotics on NO generation in response to LPS stimulation in vivo may, in part, account for the clinical efficacy of macrolides on chronic inflammatory diseases. This conclusion may be supported by 

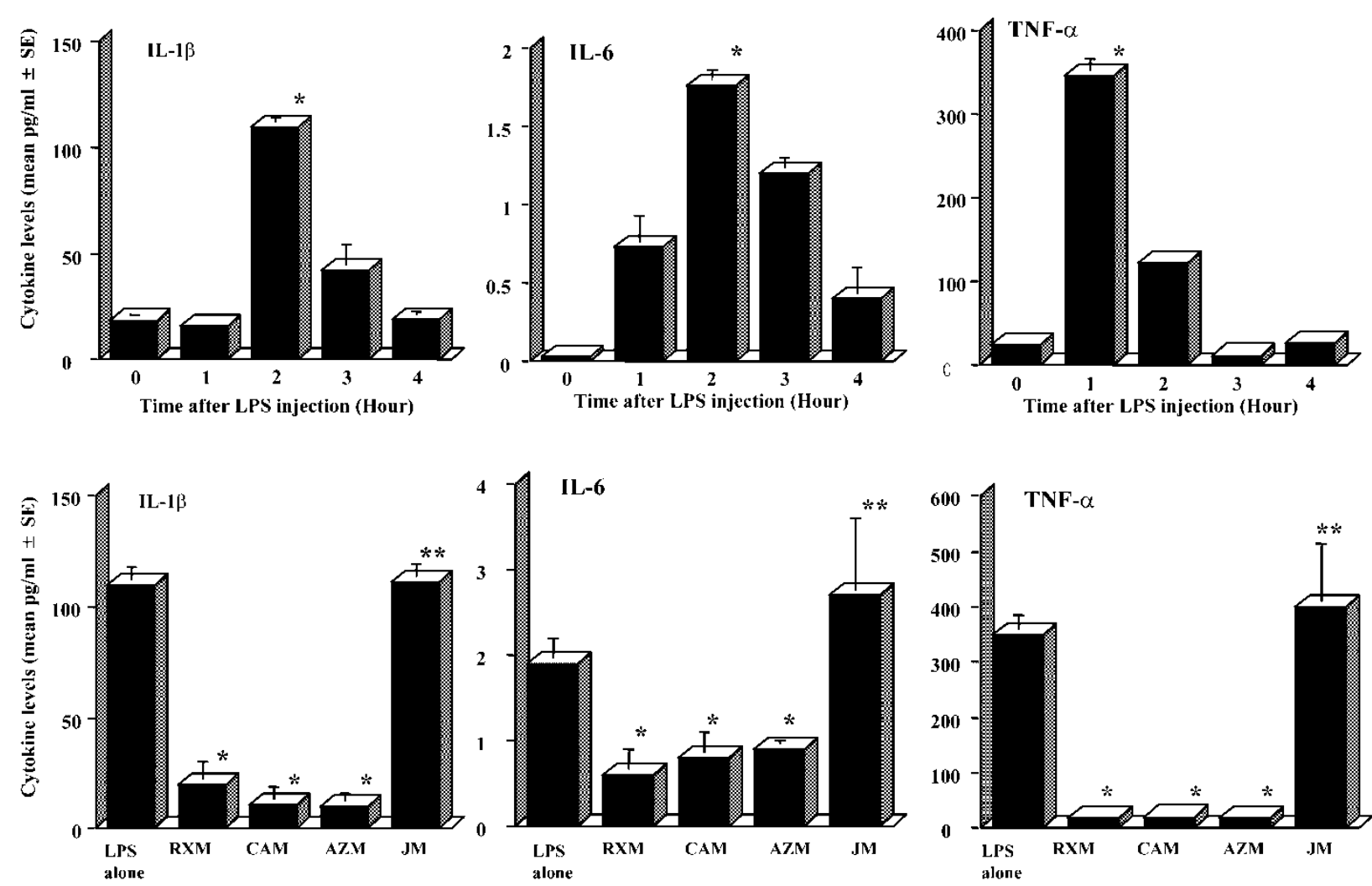

FIG. 5. Influence of macrolide antibiotics on pro-inflammatory production in response to LPS injection. ICR mice were administered orally with either RXM, CAM, AZM, or JM once a day for 4 weeks. The mice were then injected intraperitoneally with $5.0 \mathrm{mg} / \mathrm{kg}$ of LPS, and plasma cytokine levels were examined. Upper panels, the time course responses of cytokine productions, expressed as the mean $(\mathrm{pg} / \mathrm{ml}) \pm$ standard error of five mice. *Significant as compared with cytokine level before LPS injection. Lower panels, the influence of macrolide antibiotics on cytokine productions. IL-1 $\beta$ and IL- 6 levels in plasma were examined $2 \mathrm{~h}$ after LPS injection. The TNF- $\alpha$ level in plasma was examined $1 \mathrm{~h}$ after LPS injection. Data expressed as the mean $(\mathrm{pg} / \mathrm{ml}) \pm$ standard error of five mice. ${ }^{*}$ Significant as compared with LPS alone; ${ }^{* *}$ not significant as compared with LPS alone.

the following observations: (1) long-term (4 weeks), but not short-term (2 weeks), administration of 14- membered macrolide antibiotics (RXM and CAM) could suppress NO generation in vivo; and (2)
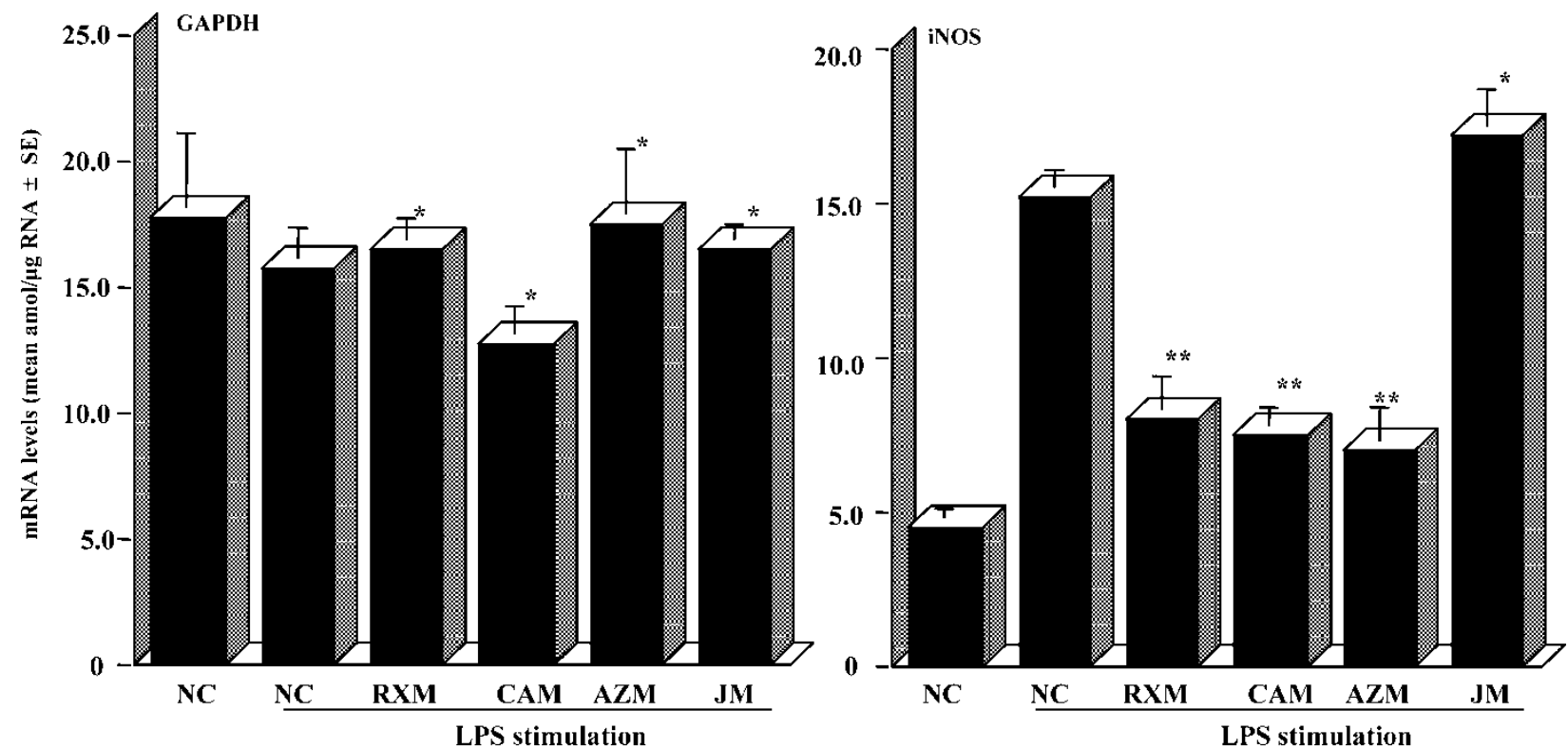

FIG. 6. Influence of macrolide antibiotics on iNOS mRNA expression in lung tissues. ICR mice were orally administered with either RXM, AZM, CAM, or JM once a day for 4 weeks. The mice were then injected intraperitoneally with $5.0 \mathrm{mg} / \mathrm{kg}$ of LPS, and lung tissue was obtained $6 \mathrm{~h}$ later for mRNA expression. NC, normal control. * Not significant compared with normal controls with LPS injected; ** significant compared with normal controls with LPS injected. 
treatment with the 16-membered macrolide antibiotic (JM), which is ineffective in clinical treatment, ${ }^{2}$ did not show any suppressive effects on NO generation. Recent reports clearly showed that long-term use of the 15-membered macrolide antibiotic (AZM) could improve lung function in patients with cystic fibrosis, which is a chronic inflammatory airway disease in Caucasians. ${ }^{3,4}$ These reports, and the present results showing the suppressive activity of AZM on NO generation, may also support the conclusion already described.

$\mathrm{NO}$ is generated in response to pro-inflammatory cytokine stimulations in a number of cell types (e.g. immune cells and fibroblasts), following induction of the inducible form of nitric oxide synthase, iNOS. ${ }^{11,19}$ Our previous work clearly showed that pre-treatment of mice with RXM decreases the ability of immune cells, such as $\mathrm{T}$ cells and macrophages, to produce pro-inflammatory cytokines induced by LPS injection, when the agent was administered into mice for longer than 4 weeks. ${ }^{5,10}$ From these reports, it is reasonable to speculate that pre-treatment of mice with macrolide antibiotics for 4 weeks decreases LPSinduced pro-inflammatory cytokine production and results in inhibition of NO generation. This speculation was supported by the present results showing that pro-inflammatory cytokine levels in plasma obtained from mice treated with macrolide antibiotics except for JM was lower than that from non-treated mice. iNOS, not present in quiescent cells, is often induced by inflammatory stimulations, and mediates the high levels of NO generation for long periods, resulting in tissue injury and mutations in cells. ${ }^{11,20,21}$ Recent reports have clearly shown that drugs, such as rebamipide $^{22}$ and thiaton ${ }^{23}$, inhibit the ability of iNOS to produce NO, and result in the prevention of intestinal damages caused by free radicals including NO. These reports leave open the question of whether the suppressive activity of macrolide antibiotics used in this study on NO production is due to its inhibitory action of iNOS generation by iNOS mRNA, or its suppression of iNOS activity to produce NO. We then examined iNOS mRNA expression in lung tissues. The present results clearly show that long-term administration of macrolide antibiotics could suppress iNOS mRNA expression, which is enhanced by LPS stimulation.

Recently, much attention has focused on the toxicity of iNOS. ${ }^{19-25}$ Induction of excessive iNOS produces endothelial cell injury and inhibits cellular respiration, which can lead to cell dysfunction and cell death. ${ }^{19,25}$ It is also observed that iNOS could accelerate the production of a large amount of superoxide, which readily reacts with hydrogen to form the most toxic molecule, hydroxyl radical. ${ }^{25}$ The present results clearly show the inhibitory effects of macrolide antibiotics on iNOS mRNA expression, suggesting that these agents can cause a decrease in
iNOS levels in cytosole and result in both suppression of superoxide generation and prevention of tissue injury in airway tracts.

The conclusion restated is as follows. The suppressive effects of macrolide antibiotics, except for $\mathrm{JM}$, on $\mathrm{NO}$ generation from fibroblasts may be one of the mechanisms leading to the favorable modification of airway inflammation in the macrolide therapy. This conclusion may be supported by clinical observations during the low-dose and long-term administration of macrolide antibiotics, showing the ineffectiveness of JM on airway inflammatory diseases. ${ }^{2}$

\section{References}

1. Iino $\mathrm{Y}$, Toriyama $\mathrm{M}$, Kudo $\mathrm{K}$, et al. Erythromycin inhibition of lipopolysaccharide-stimulated tumor necrosis factor alpha production by human monocytes in vitro. Ann Otol Rhinol Laryngol 1992; 101(Suppl 157): $16-20$.

2. Keicho N, Kudoh S. Diffuse panbronchiolitis: role of macrolides in therapy. Am J Respir Med 2002; 1: 119-131.

3. Jaffe A, Francis J, Rosental M, et al. Long-term azithromycin may improve lung function in children with cystic fibrosis. Lancet 1998; 351 420

4. Altschuler EL. Azithromycin, the multidrug-resistant protein, and cystic fibrosis. Lancet 1998; 351: 1286.

5. Suzaki H, Asano K, Ohki S, Kanai K, Mizutani T, Hisamitsu T. Suppressive activity of a macrolide antibiotic, roxithromycin, on proinflammatory cytokine production in vitro and in vivo. Med Inflamm 1999; 8: 199-204

6. Asano K, Kamakazu K, Hisamitsu T, Suzaki H. Modulation of Th2 type cytokine production from human peripheral blood leukocytes by a macrolide antibiotic, roxithromycin, in vitro. Int Immunopharmac 2001; 1: $1913-1921$.

7. Ichikawa Y, Koga H, Tanaka M, et al. Neutrophilia in bronchoalveolar lavage fluid of patients with diffuse panbronchiolitis. Chest 1990; 98: 917-923.

8. Shimane T, Asano K, Suzuki M, Hisamitsu T, Suzaki H. Influence of a macrolide antibiotic, roxithromycin, on mast cell growth and activation in vitro. Med Inflamm 2001; 10: 232-332.

9. Muranaka H, Suga M, Sato K, et al. Superoxide scavenging activity of erythromycin-iron complex. Biochem Biophys Res Commun 1997; 232: $183-187$.

10. Konno S, Adachi M, Asano K, et al. Influence of roxithromycin on cellmediated immune responses. Life Sci 1992; 51: PL107-PL112.

11. Tayler BS, Geller DA. Regulation of the inducible nitric oxide synthase (iNOS) gene. In: Salvemin D, Billiar TR, Vodovota Y, eds. Nitric Oxide and Inflammation. Basel: Birkhauser Verlag, 2001: 1-27.

12. Moncada S, Palmer RM, Higgs EA. Nitric oxide: physiology, pathophysiology, and pharmacology. Pharmacol Rev 1991; 43: 109-142.

13. Lundberg JON, Farkas-Szallasi T, Weitzberg E, et al. High nitric oxide production in human paranasal sinuses. Nat Med 1995; 1: 370-373.

14. Zoritch B. Nitric oxide and asthma. Arc Dis Child 1995; 72: 259.

15. Kooy NW, Royall JA, Ye YZ, Kelly DR, Beckman JS. Evidence for in vivo peroxinitrite production in human acute lung injury. Am J Respir Crit Care Med 1995; 151: $1250-1254$.

16. Ianaro A, Ialenti A, Maffia $\mathrm{P}$, et al. Anti-inflammatory activity of macrolide antibiotics. J Pharmacol Exp Ther 2000; 292: 156-163.

17. Asano K, Kamakazu K, Hisamitsu T, Suzaki H. Suppressive activity of macrolide antibiotics on nitric oxide production from nasal polyp fibroblasts in vitro. Acta Otolaryngol 2003; 123: $1-6$.

18. Kudoh S, Uetake T, Hagiwara $\mathrm{K}$, et al. Clinical effects of low-dose and long-term erythromycin chemotherapy on diffuse panbronchiolitis. Nibon Kyobu Shikkan Gakkai Zasshi 1987; 25: 63-69.

19. Cuzzocre $S$. Role of nitric oxide and reactive oxygen species in arthritis. In: Salvemin D, Billiar TR, Vodovota Y, eds. Nitric Oxide and Inflammation. Basel: Birkhauser Verlag, 2001: 145-160.

20. Ferdinandy P, Schulz R. Role of nitric oxide, superoxide, and peroxinitrite in myocardial ischemia-reperfusion injury and ischemic preconditioning. In: Salvemin D, Billiar TR, Vodovota Y, eds. Nitric Oxide and Inflammation. Basel: Birkhauser Verlag, 2001: 191-206.

21. Yermilov V, Rubio J, Ohshima H. Formation of 8-nitroguanin in DNA treated with peroxinitrite in vitro and its rapid removal from DNA by depurination. FEBS Lett 1995; 376: 207-210.

22. Mizoguchi H, Ogawa Y, Kanatsu K, et al . Protective effect of rebamipide on indomethacin-induced intestinal damage in rats. $J$ Gastroenterol Hepatol 2001; 16: 1112-1119. 
23. Kunitaka T, Miyazawa T, Kanatsu K, Kato S, Takeuchi K. Protective effect of thiaton, an antispasmodic drug, against indomethacin-induced intestinal damage in rats. Jpn J Pharmacol 2002; 88: 45-54

24. Palmer RMJ, Bridge L, Foxwell NA, Moncada S. The role of nitric oxide in endothelial cell damage and its inhibition by glucocorticoids. $\mathrm{Br} \mathrm{J}$ Pharmacol 1992; 105: 11-12.
25. Xia Y, Zweier JL. Superoxide anion release from inducible nitric oxide synthase. In: Salvemini D, Billiar TR, Vodovotz Y, eds. Nitric Oxide and Inflammation. Basel: Birkhauser Verlag, 2001: 27-39.

Received 23 April 2003

Accepted 12 May 2003 


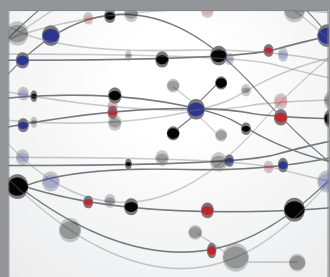

The Scientific World Journal
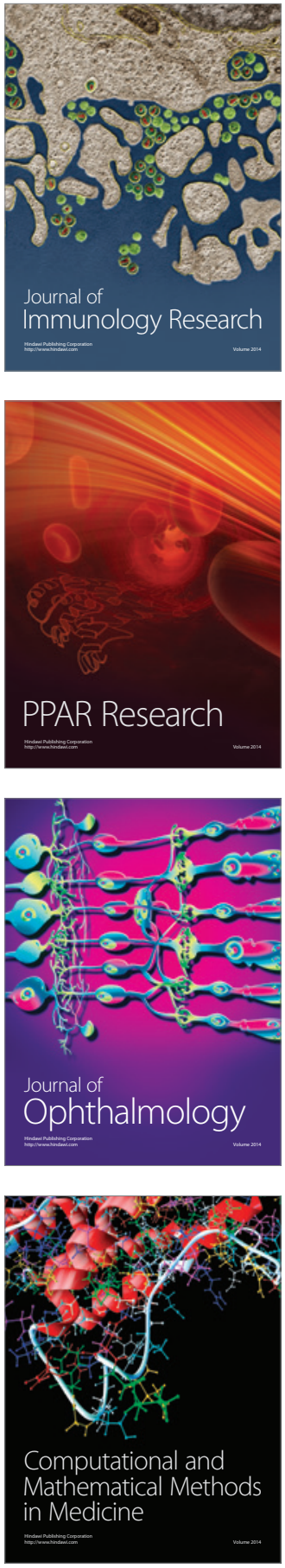

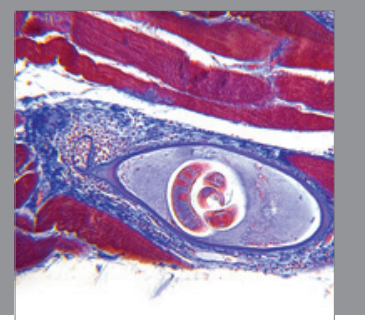

Gastroenterology

Research and Practice
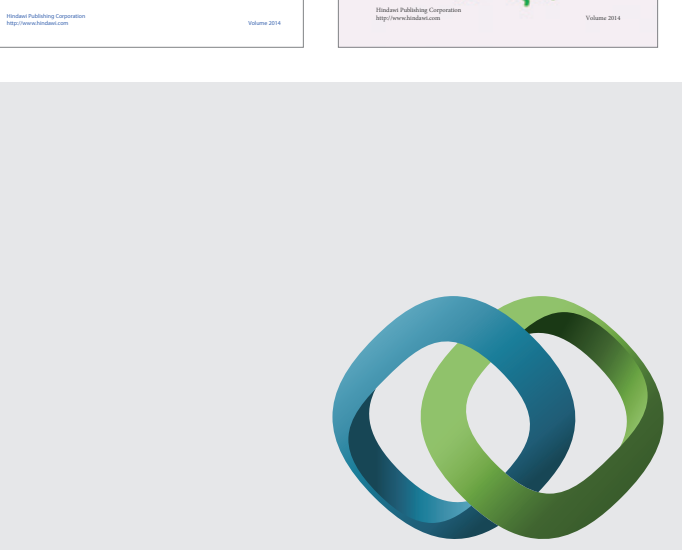

\section{Hindawi}

Submit your manuscripts at

http://www.hindawi.com
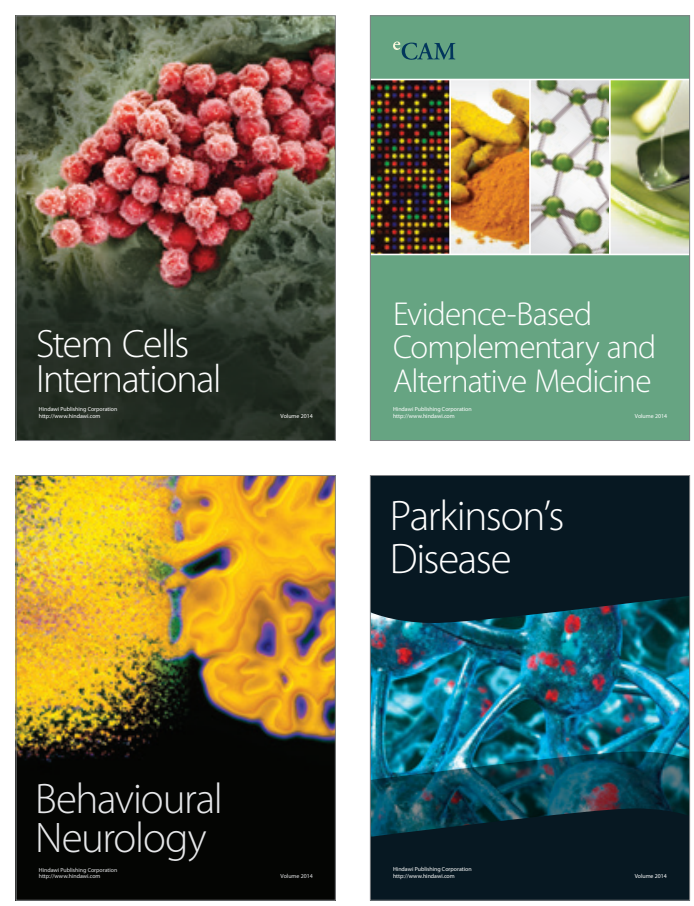

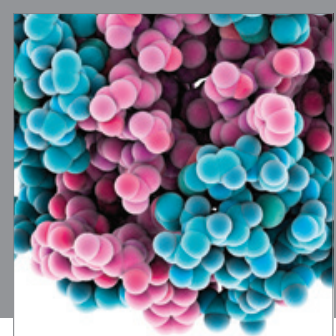

Journal of
Diabetes Research

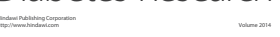

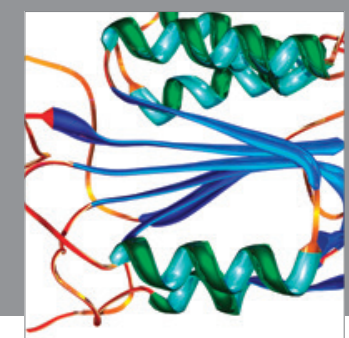

Disease Markers
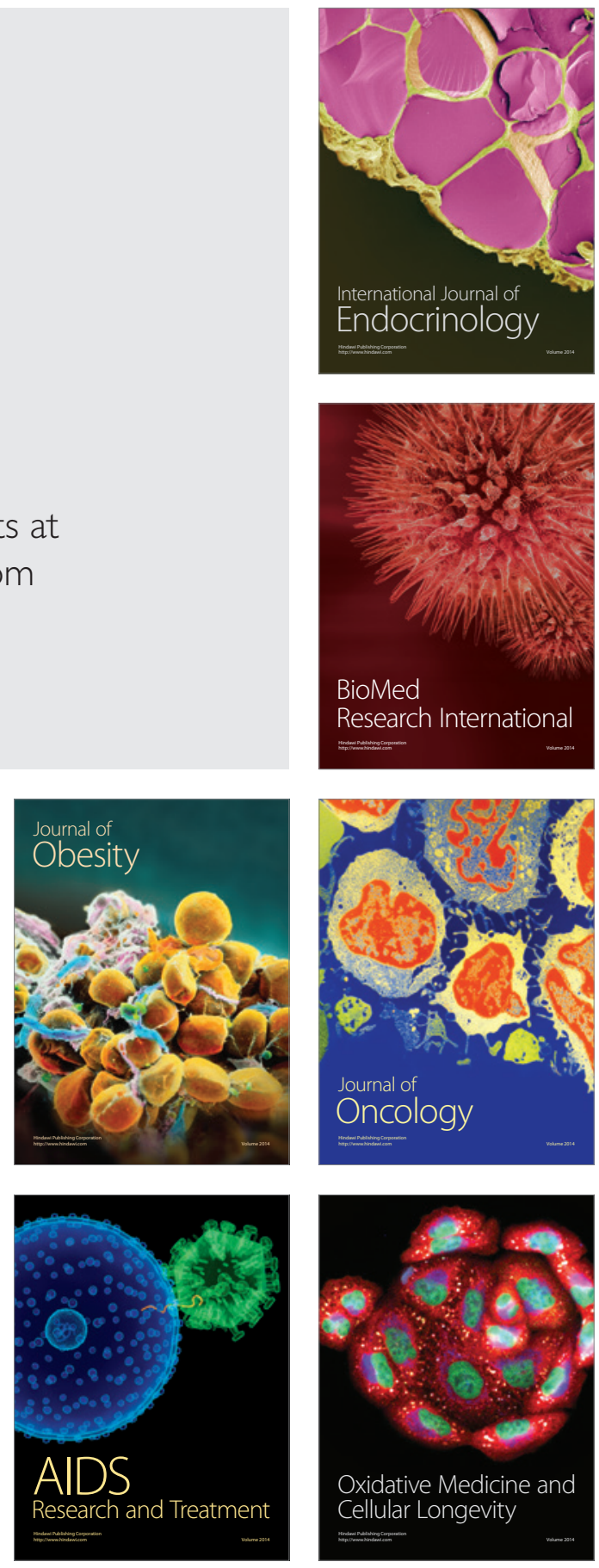